This is the peer reviewed version of the following article: Harder R, Kalmykova Y, Morrison G, Feng $F$, Mangold M, Dahlén L (2014) Quantification of goods purchases and waste generation at the level of individual households, Journal of Industrial Ecology 18(2):227-241, which has been published in final form at http://dx.doi.org/10.1111/jiec.12111. This article may be used for non-commercial purposes in accordance with Wiley Terms and Conditions for Self-Archiving.

\title{
Quantification of goods purchases and waste generation at the level of individual households
}

\author{
Robin Harder ${ }^{\mathrm{a}}$, Yuliya Kalmykova ${ }^{\mathrm{a}}$, Gregory Morrison ${ }^{\mathrm{a}}$, Fen Feng, ${ }^{\mathrm{a}, \mathrm{b}}$, Mikael \\ Mangold ${ }^{\mathrm{a}}$, Lisa Dahlén ${ }^{\mathrm{c}}$ \\ ${ }^{a}$ Department of Civil and Environmental Engineering, Chalmers University of Technology, \\ Gothenburg, Sweden \\ ${ }^{\mathrm{b}}$ Uppsala University, Uppsala, Sweden \\ ${ }^{\mathrm{c}}$ Department of Civil and Environmental and Natural Resources Engineering, Luleå University of \\ Technology, Luleå, Sweden
}

SUMMARY: Quantifying differences in resource use and waste generation between individual households and exploring the reasons for the variations observed implies the need for disaggregated data on household activities and related physical flows. The collection of disaggregated data for water use, gas use, electricity use, and mobility has been reported in the literature and is normally achieved through sensors and computational algorithms. This study focuses on collecting disaggregated data for goods consumption and related waste generation at the level of individual households. To this end, two data collection approaches were devised and evaluated: (1) triangulating shopping receipt analysis and waste component analysis and (2) tracking goods consumption and waste generation using a smartphone. A case study on two households demonstrated that it is possible to collect quantitative data on goods consumption and related waste generation on a per unit basis for individual households. The study suggested that the type of data collected can be relevant in a number of different research contexts: eco-feedback; user-centered research; livinglab research; and life cycle impacts of household consumption. The approaches presented in this study are most applicable in the context of user-centered or livinglab research. For the other contexts, alternative data sources (e.g., retailers and producers) may be better suited to data collection on larger samples, though at a lesser level of detail, compared with the two data collection approaches devised and evaluated in this study.

KEYWORDS: case study, disaggregation, goods purchases, household metabolism, industrial ecology, waste generation

\section{ADDRESS CORRESPONDENCE TO}

Robin Harder: robin.harder@wetryharder.ch 


\section{Introduction}

The reduction of resource use and waste generation would be an important contribution towards mitigating global environmental and resource issues. In past decades attention has been paid to increasing efficiency in production by creating more goods and services while using fewer resources and creating less waste and pollution (Barbiroli, 2006). However, resource use and waste generation have increased as a result of population growth and generally rising consumption levels (Giljum et al., 2009; Kitzes et al., 2008). It is increasingly being recognized that efficiency alone is not enough (Frye-Levine, 2012; Korhonen and Seager, 2008) and needs to be complemented with other elements, such as sufficiency (Cooper, 2005), which in turn need to be facilitated by technical, economic, social, political, and personal changes (Weinstein et al., 2013).

Many resource and waste flows are ultimately caused by household consumption (Baccini and Bader, 1996) and household consumption is highlighted as a key area requiring attention (Doyle and Davies, 2013). Several studies have calculated the environmental impacts of private consumption (Benders et al., 2012; Hertwich, 2011; Tukker et al., 2010; Tukker and Jansen, 2006; Bin and Dowlatabadi, 2005). These studies normally build on national statistics and aim at determining the relative importance of different consumption areas - such as food, shelter, clothing, mobility, and leisure - in terms of environmental and resource impacts (Hertwich, 2011). Tukker and Jansen (2006) for instance found that food, housing and related energy use, and transport are responsible for more than $70 \%$ of the total life-cycle impacts of final household and government consumption.

Other studies have compared mass and energy flows for different neighborhoods based on official statistics and surveys (Codoban and Kennedy, 2008), or have focused on quantifying and characterizing household waste generated in different neighborhoods or municipalities through waste component analysis (Lebersorger and Beigl, 2011; Dahlén and Lagerkvist, 2008; Dahlén et al., 2007; Sterner and Bartelings, 1999). The former studies aim at evaluating resource consumption and waste generation patterns, the latter ones the performance of different municipal waste collection systems. Both types of studies are generally designed in such a way as to obtain data representative of a given neighborhood (e.g., villa area, area with apartment blocks, area with a property close collection system, area with a drop-off collection system). This usually requires stratified sampling, so that spatial and (shortterm) temporal variations at the level of individual households are evened out. Comparing resource and waste flows at the neighborhood or city scale certainly reveals differences between different household types, neighborhoods, or municipalities, but does not reveal differences between individual households, notably with regard to how different household activities and household practices influence the magnitude of resource and waste flows.

Reid and colleagues (2010) emphasized the importance of the (individual) household as unit of analysis for studying pro-environmental behavior. Various studies have analyzed and compared resource use and environmental impacts of different individual households through for example modeling (Stamminger, 2011; 
Baker et al., 2007), surveys (Moll et al., 2005; Carlsson-Kanyama et al., 2002; Holden, 2004; Hunter et al., 2006; Kotakorpi et al., 2008), or manual waste sorting and weighing by household members themselves (e.g., Bandara et al., 2007; Abu Qdais et al., 1997). Studies focusing on individual households normally aim at revealing the differences in resource use and waste generation between different individual households or household types. Ultimately, resource consumption and waste generation by individual households is driven by different household activities and practices. Research directions focusing on household activities and practices include the investigation of behavioral aspects of consumption and consumption choices (Evans, 2011; Reid et al., 2011; Isenhour, 2010; Holden and Linnerud, 2010; Gilg et al., 2005), close examination of household practices (Doyle and Davies, 2013; Kuijer and de Jong, 2012; Gram-Hanssen, 2010), co-management of household practices (Strengers, 2011; Bulkeley and Askins, 2009; Bulkeley and Gregson, 2009), or persuasive technology and virtual agents (McCalley el al, 2011; Roubroeks et al., 2011). The studies focusing on individual households or household practices often investigate impacts on one specific flow, e.g. water, electricity, or waste.

The present study was motivated by an attempt to measure and compare multiple flows of matter and energy simultaneously for a number of individual households at a level of detail so that they can be related to different household activities and practices, or products consumed. This requires disaggregated sensing at the level of individual appliances, fixtures, or products, respectively. Human-computer interaction (HCI) has contributed substantially to enabling data collection at this high level of disaggregation through the development of advanced sensing technology and disaggregation algorithms, mainly by developing and testing eco-feedback technology (Froehlich, 2011; Sundramoorthy et al., 2011). A high degree of disaggregation was achieved for water use (Larson et al., 2009), electricity use (Gupta et al., 2009), gas use (Cohn et al., 2010), and mobility (Froehlich et al., 2009) through physical sensors and computational algorithms. The latter study also required user input in addition to the sensor data.

The collection of highly disaggregated data on goods consumption and related waste generation at the level of individual households and products, however, is more difficult than metering water or electricity supplied in public mains, mainly due to supply and discharge through several pathways as well as the heterogeneous composition of the related physical flows. As a result of the variety of pathways, quantification of the respective physical flows cannot be determined by means of a single sensor. Perhaps the most direct way of recording goods consumption and waste generation is through household documentation in the form of a diary or journal. This approach is used in market research studies or studies aiming at estimating resource use, waste generation and environmental impacts of individual households (e.g. Holden, 2004; Hunter et al., 2006; Kotakorpi, 2008). However, diary- and journalbased approaches do not normally estimate product flows on a per unit basis. Studies where household members sorted waste into different fractions and recorded the weight on a daily basis (e.g., Bandara et al., 2007; Abu Qdais et al., 1997) do not provide data on a per unit basis either. 
The overall aim of the present study was to develop approaches to collect consumption and waste generation data on a per unit basis. Two such approaches were devised and evaluated throughout this study. The specific aim of the study was (1) to evaluate these two approaches for two households, thereby identifying opportunities and limitations; (2) to discuss the usability and applicability of the approaches and the data collected in different research contexts; and (3) to highlight possible further developments that may simplify data collection for a larger number of households and/or for a longer sampling period.

\section{Methodology}

Two approaches for the collection of disaggregated data on goods consumption and waste generation were devised. The first approach aimed at the minimum involvement of, and disturbance to households. In particular, households should not be required to keep a journal or otherwise record the amount of products consumed and waste disposed of. Furthermore, data collection should be possible without having to obtain data from producers or retailers. Given this design space, two main data sources came into consideration in the first approach: shopping receipts and waste component analysis. The second approach focused on the collection of disaggregated data directly by members of the household through a smartphone WebApp.

In order to test and evaluate the two data collection approaches, a case study on two households in Gothenburg, Sweden, was performed. Two households of the researchers involved in the project were chosen as test households. This choice admittedly makes it impossible to judge whether other households are willing to engage in such data collection. The advantage of the approach was full control and feedback on the process of data collection, which allowed the methods themselves to be fully evaluated. Furthermore, the focus of this study was on method evaluation rather than on data comparison, which justifies the bias introduced by selective sampling. Household A consisted of a detached house with a floor space of $300 \mathrm{~m}^{2}$, two adults, five children (aged 4-18), one dog and one cat; household B consisted of an apartment with a floor space of $70 \mathrm{~m}^{2}$ inhabited by one adult. Note that single households represent roughly $50 \%$ of Swedish households whereas families with three or more children represent about $3.5 \%$ of Swedish households (SCB, 2013).

\subsection{Triangulating Shopping Receipt Analysis and Waste Component Analysis}

Most consumer goods, at least in industrialized countries, are purchased through retail trade and come with some kind of packaging. Two obvious sources of information on goods consumption are shopping receipts and disposed packaging. The overall organization of shopping receipts in Sweden is very similar; header and footer include shop details, payment details, purchase date and total price of the purchases, whereas the main body of the receipt lists the individual articles purchased. The type of information provided for the individual articles purchased, however, varies considerably from shop to shop. Ideally, the article number (e.g., GTIN-13), article description, quantity and price are printed on the receipt. Yet only a few shops include article numbers, and information on quantities is often incomplete, e.g. weight 
indications are only stated for products bought by weight rather than by package. Waste component analysis, if done for individual households, reveals disaggregated information on the quantity and type of waste disposed of. The disposed packaging, however, also holds relevant information on type and amount of products bought. The combination of the two data sources is illustrated in figure 1.

Shopping receipt and waste component analysis were combined in order to estimate goods consumption and related waste generation. Both households were asked to collect (1) shopping receipts relevant to purchases of consumer goods, (2) selected recyclables (i.e., glass, metal, paper, cardboard, plastic) in a separate container on a daily basis, and (3) food-related organic waste in four different fractions per day (i.e., vegetable waste and peelings, fruit waste and peelings, wasted food, other food-related organic waste). The research team analyzed the different data sources and transferred the information to a database tailored to this purpose. Shopping receipts and recyclables were collected for twelve weeks (17 March to 10 June, 2012) and organic waste was collected for five weeks (3 May to 7 June, 2012). All relevant information on the shopping receipts was manually transferred into the database. Collected recyclables were first grouped into two categories: standardized packaging items (i.e., packaging material from articles that can be identified by a product barcode, usually in GTIN-13 format) and the remaining recyclables. For standardized packaging items, product barcode, amount and date of disposal were recorded in the database. Furthermore, product name, manufacturer, manufacturing country as well as the weight of different fractions of the packaging (i.e., glass, metal, paper, cardboard, plastic) were determined and stored in the database along with the respective product barcode in case the product did not already exist in the database. The remaining recyclables were grouped into ten types (i.e., newspaper, magazine, commercial, envelope, unspecified paper, unspecified cardboard, unspecified plastic, unspecified metal, unspecified glass, unspecified wood) and the weight of each type was registered along with its disposal date. Organic waste samples were weighed as wet weight and as dry weight after drying to constant weight in an oven at $120^{\circ} \mathrm{C}$ for 24 hours. Wet weight, dry weight, fraction and generation date of the samples were stored in the database.

\subsection{Tracking Goods Consumption and Waste Generation using a Smartphone (FoodWatch)}

A smartphone WebApp was developed in order to simplify the documentation of goods consumption and related waste generation, and hence facilitate the collection of disaggregated data directly by members of the household. The application, henceforth referred to as FoodWatch, was conceived to track purchase, consumption, and disposal of food products in particular. One special focus when developing FoodWatch was that it should enable the consistent tracking of specific products from entering to leaving the household without the need to triangulate data from different data sources. To this end, a sequence barcode (GTIN-13 format) was introduced that consisted of 4 digits identifying the household and 5 digits identifying the specific article purchased. Note that for instance, three identical milk packages (i.e., same 
GTIN-13 product barcode) bought on the same day would receive three different unique sequence barcodes. The sequence barcode thus allows the unambiguous identification of each single good (for products packed in a standardized packaging item) or batch of goods (for products not packed in a standardized packaging item) entering the household, whether purchased or acquired otherwise. Using FoodWatch, a dataset was collected at household B from 30 December 2012 until 16 January 2013. Note that this data collection period is different from the one for the triangulation approach since the WebApp was developed later, partly in response to some of the shortcomings of the triangulation approach (i.e. difficulty of relating input and output data).

Each good or batch of goods entering the household was furnished with a sticker carrying the unique sequence barcode. The goods were then added to the inventory by scanning the sequence barcode and the product barcode, or alternatively choosing a product group in case no product barcode was available (figure 2). Furthermore, goods where information on the weight was unavailable through shopping receipt or packaging were weighed manually. Once in the household, products can be taken outside of the household again, consumed in the household, or disposed of. Each of these activities was recorded using the FoodWatch application by scanning the sequence barcode, manually weighing the product or specific fraction thereof, and indicating whether the product or fraction was taken outside of the household (e.g. as a present or for consumption elsewhere), consumed in the household, or disposed of (figure 2). In either case it was removed from the inventory. For example, preparing a grated carrot salad resulted in the consumption of carrots, oil, vinegar, and spices as well as the disposal of organic waste (peelings). Note that disposal of packaging material was not considered in this approach.

\subsection{Product Classification}

To increase the usability of the database, each good was assigned one out of 242 product groups (e.g. fresh bread, fruit juice, fresh tomato, toothpaste, yoghurt, wine). These product groups in turn were related to COICOP (Classification of Individual Consumption by Purpose) classes and CPA-2008 (Classification of Products by Activity) classes, thereby allowing for data aggregation on COICOP levels 1-3 and CPA-2008 levels 1-6.

\section{Results}

This section presents some of the experiences and findings emerging from the testing and evaluation of the two data collection approaches. The extent of data collection is summarized in table 1. Although this study focused primarily on devising and evaluating two data collection approaches rather than on collecting a representative dataset, selected parts of the dataset obtained during methods testing are presented at this point in order to illustrate the potential for data analysis and applications of such a dataset. 


\subsection{Triangulating Shopping Receipt Analysis and Waste Component Analysis}

The main challenges encountered when using the first data collection approach were related to the estimation of overall product flows: relating disposed packaging items to a corresponding purchase and incomplete weight information (i.e. lack of weight indication on both the shopping receipt and the product packaging) were the main problems. Although data obtained from shopping receipts and waste component analysis are complementary, it was often difficult to relate a specific shopping receipt item (i.e. product as stated on the shopping receipt) to its corresponding packaging item (i.e. product as described on the product packaging). This is because the item identifications on shopping receipts are often not identical with the names on the product packaging. Furthermore, different supermarkets state different item descriptions on the shopping receipts to refer to the same product. Finally, purchased products can be placed in stock and products used can come from that stock; this further complicates linking data sources representing input and output estimates. Overall, just under one half of the standardized product packages disposed of could be assigned to a specific purchase or shopping receipt item (a similar situation for both households). Even though a web-based platform was developed to optimize data collection, the time required for data collection was substantial: approximately one hour per household and day was required: shopping receipt analysis took close to 10 minutes per household and day; waste component analysis of recyclables disposed took approximately 20 minutes per household and day; and processing of organic waste required another 30 minutes per household and day. The time required per household was not proportional to household size as several steps in the analyses require similar amounts of time independent of the number of purchases or the amount of waste. Household A, given the larger amounts of waste, delivered the waste to the university facilities by car every second or third day (organic waste was stored in a refrigerator until delivery); the time requirements were about 30 minutes per delivery. Members of household B delivered the waste on a daily basis on their regular way to work.

When it comes to the estimation of product flows from triangulating the two data sources, four cases can be distinguished: (1) food products that need to be consumed or processed within several days after purchase (e.g. strawberries, cherries), (2) food products that can be stored for extended periods after purchase but need to be consumed within several days after opening the package (e.g. canned food, fruit juices), (3) products that can be stored for extended periods after purchase even after the packaging was opened (e.g. sugar, flour, potatoes, apples), and (4) non-food products. For products that are normally consumed within several days after purchase (e.g., vegetables, fruits), changes in stock can be neglected, and the product flow can be estimated based on a combination of input data (shopping receipt analysis) and output data (waste component analysis), unless the products are deep-frozen or processed (e.g. production of jam) instead of consumed. However, care needs to be taken to avoid double counting for products bought by weight. On the one hand, such products often have no packaging or just a small plastic bag with no further information provided on it whilst information on the weight is provided on the 
shopping receipt. On the other hand, pre-packed similar products often have no weight indication on the shopping receipt but the package holds this information. Sometimes, weight information is provided both on the shopping receipt and the packaging (e.g., vacuum-packed meat products). In other cases, neither shopping receipt nor packaging holds information on the weight (e.g. fresh bread). Products that can be stored over extended periods but need to be consumed within several days after opening (e.g., fruit juices, dairy products, canned food) may be subject to a considerable time-lag between purchase and consumption. For these products, data obtained from the analysis of collected waste better reflects the actual consumption over a given period than data obtained from shopping receipts. Products that can be stored over extended periods, even if the packaging is opened, may have been purchased before and the respective packaging disposed of after the data collection period. In this case the actual consumption of product may not be captured at all. Nonfood products often do not indicate product weight, in which case an estimation of the product flows in terms of weight is not possible based on the two data sources considered. The estimation of product flows based on the two data sources is shown in table 2. Note that these values are conservative and the actual flows are likely larger.

Shopping receipt analysis allowed for a very detailed estimation of expenditure for goods down to the level of individual products or product groups. Analysis of disposed recyclables revealed which products or product groups contributed most to the generation of recyclable waste at this particular household, and whether packaging intensity (i.e. packaging weight per product weight), frequency of consumption, or both were the key driver of waste generation. It was also possible to estimate whether packaging material or used products contributed most to the total number of recyclables disposed of. For household A, for instance, glass, metal, plastic and cardboard were mainly from packaging material, whereas most paper originated from used products, mainly newspapers and magazines. The detailed analysis of foodrelated organic waste in four fractions showed considerable differences between the two households. For instance two thirds of the food-related organic waste in Household A consisted of wasted food, whilst the respective fraction was one fourth in Household B (figure 3). As data was collected on a daily basis, it was possible to estimate temporal patterns for both purchase of goods and disposal of recyclables and organic waste (figure 4). The respective flows can be analyzed per day of the week or per week.

\subsection{Tracking Goods Consumption and Waste Generation using a Smartphone}

FoodWatch, in essence being a stock control system for food products, can provide an overview of the inventory of goods in real time as well as a history of purchases, consumption, and disposal of food products. It enables precise tracking when a specific food product enters the household, when it was used and in combination with which other ingredients (table 3); and how much of it was taken outside of the home (i.e. for consumption elsewhere), consumed in the home, or disposed of, respectively 
(figure 5). Using the FoodWatch application required approximately 5 minutes per shopping or cooking event in Household B.

\section{Discussion}

In this study, two approaches for collecting disaggregated data on goods consumption and related waste generation by individual households on a per unit basis were devised and evaluated. The first approach (triangulation) aimed at minimum involvement of, and disturbance to households. In particular, households should not be required to keep documentation or otherwise record the amount of products consumed and waste disposed of. Furthermore, data collection should be possible without having to obtain data from producers or retailers. The second approach focused on facilitating the collection of disaggregated data directly by members of the household through a smartphone WebApp referred to as FoodWatch. The discussion is organized in three parts: (1) discussion of methodological considerations, (2) discussion and suggestions of relevant applications, and (3) discussion of further developments.

\subsection{Methodological Considerations}

\subsubsection{Flows Covered by the Data Collection Approaches Presented}

Ideally - at least from the perspective of a researcher-for every good moving through a household, all information regarding its detailed composition should be available as well as when and by which pathway the product entered the household, what it was used for, and when and on which pathway(s) its constituents left the household. Furthermore, when life-cycle impacts are to be considered, the material input and waste generation during manufacturing, supply and disposal of each good should ideally be known; the corresponding flows are often referred to as hidden flows as they are outside the physical system boundary of the individual household yet still attributable to a specific good and household. The triangulation approach combined shopping receipt and waste component analysis in order to estimate goods consumption and related waste generation. Data collection was thus limited to products purchased through retail and/or products contained in a packaging. In particular, goods resulting from home gardening or collected in nature were not considered. These flows can be significant for some households. Neither did the data collection approach capture goods taken out of the house for consumption after they were bought and brought into the house. Generally speaking, these and similar challenges are related to the difficulty of defining the household. On the one hand, the household could be defined as a socio-economic entity consisting of individuals who live together occupying all or part of a dwelling. On the other hand, the household could be seen as a physical entity consisting of humans, domestic animals and artifacts. The implications are that flows will be either calculated in terms of people and their activities (independent of where they induce the flows) or related to the physical household (independent of which people induce the flows). In this study, households were defined as physical entities with the physical household as system boundary. Whilst the triangulation approach is limited to the household as a physical 
entity, FoodWatch could be applied with either delimitation of the household. Further, it also covers goods resulting from home gardening or picked in nature, and it allows recording the removal of goods from the household for consumption elsewhere or further processing (e.g. making jam).

\subsubsection{Limitations and Biases of the Data Collection Approaches Presented}

The main limitations of the triangulation approach were its confinement to purchased goods (on the supply side) and goods coming in a packaging (on the disposal side), and the difficulty to establish consistent flow estimates based on input and output data. Further bias may arise when households chose not to deliver certain shopping receipts, to dispose of certain packaging elsewhere than in the waste that is collected for waste component analysis, or to reuse a certain packaging within the household instead of disposing of it straight away. Also, households may not be consistent in assigning organic waste to one of the four fractions used in this study.

Tracking consumption and disposal of food products using FoodWatch on the other hand required the integration of new habits into the practice of cooking and dealing with shopping. First of all, sequential barcodes needed to be added to each purchased good (or batch of goods) prior to adding it to the inventory. Furthermore, cooking needed to be accompanied by several instances of manually weighing ingredients. Although quite straightforward in theory and feasible in practice, the involvement required in data collection may potentially be perceived as tiresome by certain household members after a given period. As a result, participants may resort to simpler dishes to avoid extensive recording and weighing after shopping and during food preparation. The complexity of data collection could be reduced by restricting data collection to purchases only. This would reduce the involvement of the households, as there would be no need for the addition of sequential barcodes and weighing of ingredients during cooking. This simplification may be advisable if households are to be engaged in data collection for extended periods.

For both approaches, it is unclear to what extent randomly selected households would be willing to participate in a study that scrutinizes their purchases and waste generation and hence their lifestyles so comprehensively. In both approaches the household members have a certain control on what data to reveal by not providing certain shopping receipts or discharging certain waste items elsewhere, or by using FoodWatch selectively. This sense of control on the one hand probably increases the willingness of participation, but on the other hand is likely to increase bias. Previous studies on resource consumption and waste generation of individual households (Kotakorpi et al., 2008; Reid et al., 2011; Abu-Qdais, 1997) selected between 25 and 50 households. These studies did not report any difficulties in finding a sufficient number of households, but acknowledge that the recruitment and selection process may favor households with pre-existing pro-environmental commitments.

\subsubsection{Alternative Data Sources and Collection Approaches}

Both data collection approaches devised and evaluated in this study attempted to collect data that is partly available elsewhere, namely at retailers and producers. In principle, it would be possible for retailers to make available shopping receipts in 
digital form (through e-mail or customer fidelity schemes) and by this means provide much more detailed information than stated on shopping receipts. If digital shopping receipts cannot be directly obtained from retailers, at least the retailers could print article numbers (e.g. GTIN-13) on the shopping receipts. This was practiced by one of the retailers Household A bought products from. Availability of purchase data from retailers would greatly simplify both the triangulation and the FoodWatch approach, at least where unambiguous traceability is not aimed for and sequence barcodes therefore omitted. However, households buy goods from several different retailers. In this study, household A bought from 16 different stores, whereas household B bought from 12 different stores. For a complete tracking of purchases without manual data collection, data availability from each of these stores would be necessary. Purchase information could be complemented with data on product composition or packaging composition obtained from producers, where available. Note that there are also several product databases openly available (GoodGuide, 2013; OpenEAN, 2013), though incomplete. Any of these modifications would make waste component analysis redundant for the estimation of product flows when using the triangulation approach. The only function of waste component analysis left would be the quantification of food waste. Obtaining information on packaging materials and amounts would also facilitate the estimation of packaging waste generation with the FoodWatch approach, where packaging waste was not considered otherwise. The generation of packaging material might then be estimated based on the input of products. This estimation is expected to accurately capture packaging waste from standardized products as well as used products but miss out on packaging material related to non-standardized products (e.g., fruits and vegetables bought as loose weight). However, when estimating waste generation (for recyclables) through input, temporal aspects of disposal are no longer covered.

In terms of data collection efforts, the optimum case - from the perspective of a researcher-would be to receive digital information on purchases from retailers upon consent from the households, and combine this information with information on packaging obtained from producers. However, even if the data for supply of food products to households could be obtained electronically from retailers, details on the usage of the products, particularly the fractions consumed and wasted, would not be available any longer. Collection of this data would still require a separate record of the amounts consumed or wasted. For the FoodWatch approach, this process could be simplified in the future through an automatic connection between the scale and the WebApp.

It is important to note that the two data collection approaches evaluated in this study, whilst producing data partly redundant with data potentially available from retailers and producers, still provide some data that cannot be obtained from other data sources. It is therefore important to consider how different data sources could be best combined in the future in a given research context. Whereas data availability from retailers would facilitate the consideration of a larger number of households, the approaches presented in this study augment the level of detail and the type of 
information obtained. The required number of households, level of detail and type of information required depend on the research context.

\subsection{Relevance and Applicability in Different Contexts}

\subsubsection{Comparative Studies on Life-Cycle Impacts of Household Consumption}

The estimation of life-cycle impacts of the consumption of individual households requires data on the respective product flows and waste generation. Comparative studies that investigate spatial and temporal consumption and waste generation patterns and variations among different households require a larger number of households in order to be representative and significant. Life-cycle impacts of household consumption can then be calculated based on estimated material and energy flows, and input-output tables. Material and energy flows were often estimated using diaries or questionnaires (Holden, 2004; Hunter et al., 2006; Kotakorpi et al., 2008). Hertwich (2005) highlights that differences implied by consumption choices are often not properly taken into account by the average values available in inputoutput tables. In case life-cycle data were further disaggregated in order to take into account consumption choices, the collection of data on a per unit basis, the level of disaggregation obtained through the methods described in this study, would be the logical counterpart. Given sufficient personnel, the triangulation approach is applicable for several tens of households; yet it is advisable to skip the determination of the dry weight of the biowaste fractions, as this was the most time consuming and least relevant step. The FoodWatch approach, if restricted to recording purchases only, is applicable likewise. However, if no disaggregated life-cycle data are available, the two approaches evaluated in this study provide more detail than necessary and diary or questionnaire based approaches may be more practical.

\subsubsection{Eco-Feedback}

Eco-feedback refers to providing households with data on how everyday activities affect the environment through resource use and waste generation. Primarily, ecofeedback is meant to facilitate informed decision-making. Feedback of water and energy consumption to individual households and the effect of such feedback have been thoroughly investigated elsewhere (Jain et al., 2013; Froehlich, 2011; Sundramoorthy et al., 2011). In the context of eco-feedback, timeliness of data collection is important, that is, data need to be collected in real-time or close to realtime and data collection should be as automated as possible. The triangulation approach evaluated in this study does not meet these criteria. FoodWatch, however is an adequate alternative in this context. In the meantime further functionalities have been developed, particularly the integration of footprints such as the carbon footprint or the water footprint. Interesting research questions include how the users' knowledge on product and waste flows and related environmental impacts (footprints) influences consumption choices and waste behavior. In this regard the temporal patterns (figure 4) are relevant as they enable the identification of activities with a particularly high environmental impact or waste generation. 


\subsubsection{User-centered Research}

Finally, user-centered research focuses on understanding and influencing household practices and by nature investigates a smaller number of households (Scott et al., 2012). Interesting research questions emerge when looking into household practices related to the storage and preparation of food. Of particular interest could be the identification of practices that lead to extensive food waste and the investigation and evaluation of mitigation measures. To this end, FoodWatch would be highly relevant and allow the evaluation of how innovations or changes in household practices affect consumption and waste generation.

\subsection{Further Developments and Outlook}

When it comes to a further development of the data collection approaches presented in this study, a number of issues need to be addressed. These issues mainly relate to how different stakeholders perceive the value and risks of data availability at such a high level of detail. First and foremost, aspects of personal integrity need to be touched upon as the data collection methods applied and suggested in this study not only reveal physical flows but also many details of the lifestyles of participating households. Second, changes in legislation on data disclosure (Thaler and Tucker, 2013) could imply a significant boost for data availability on household consumption. Third, a more widespread application of RFID tags or other advanced sensors (Omenetto et al., 2012) could open up further possibilities for data collection in individual households. Giving household members access to the data collected may provide an incentive to participate in a study. A remaining concern is how the exchange of data could be organized in accordance with legislation on data privacy. In this regard it is crucial to clarify data ownership questions beforehand. Furthermore, in case several parties are involved in data collection, it may be advisable to organize data exchange in such a way that there are certain limitations regarding the extent of data accessibility that are inherent in the system, so that every party involved (e.g. retailers, producers, households, researchers) retains a sense of control over which data is shared, when, and with whom.

\section{Conclusions}

Using the two data collection approaches devised and evaluated in this study, it was possible to collect highly disaggregated data on goods consumption and waste generation on a per unit basis. The triangulation approach enabled data collection without significant involvement of the test households and without obtaining information directly from retailers or producers. FoodWatch enabled the collection of highly disaggregated (per unit) data on purchase, consumption and disposal of food products by the households themselves. The study also exposed a number of potential biases and shortcomings inherent to the two approaches that need to be addressed before considering the application of any of the two approaches on a larger scale. It is also important to find a tradeoff between acceptable bias and required level of detail, and to carefully consider which level of detail is required for a larger study in a specific context. With the triangulation approach a lesser level of detail can be 
achieved and it is more difficult to establish consistent estimates of product flows. Involving households through household documentation facilitated by a smartphone application allows for a much higher level of detail but requires more commitment by the participating households.

The proposed approaches are particularly promising in the context of user-centered or living-lab research with small sample sizes and a high demand on the level of detail of the data collected. For comparative studies of the calculation of environmental lifecycle impacts and eco-feedback, it is important to consider if data could be obtained from alternative data sources, such as retailers, in order to facilitate larger sample sizes. Finally, questions regarding personal integrity and households' willingness to participate in such a study need to be carefully considered when collecting and collating this type of data.

\section{ACKNOWLEDGEMENTS}

The two anonymous test households are thanked for their willingness to participate in this case study and facilitating data collection and delivering the collected waste at the university facilities. We thank the following people whose questions, comments and information helped shape our research: Christine Räisänen, Leonardo Rosado, and Johan Thörn (at Chalmers University of Technology). We also thank the four external reviewers for their valuable and critical comments and suggestions that helped improve this manuscript.

\section{FIGURES}

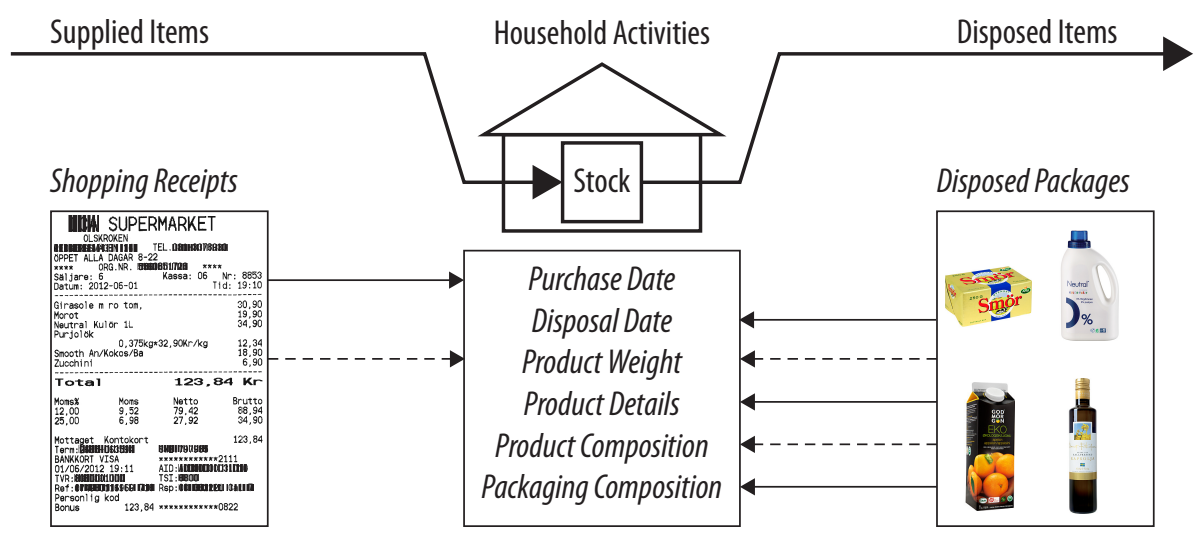

Figure 1: Combination of data sources. Information obtained from shopping receipts and disposed packages is combined to estimate product flows and related waste generation. Solid lines indicate that information is available for all items, whilst dashed lines indicate that information is only available for some of the items. 


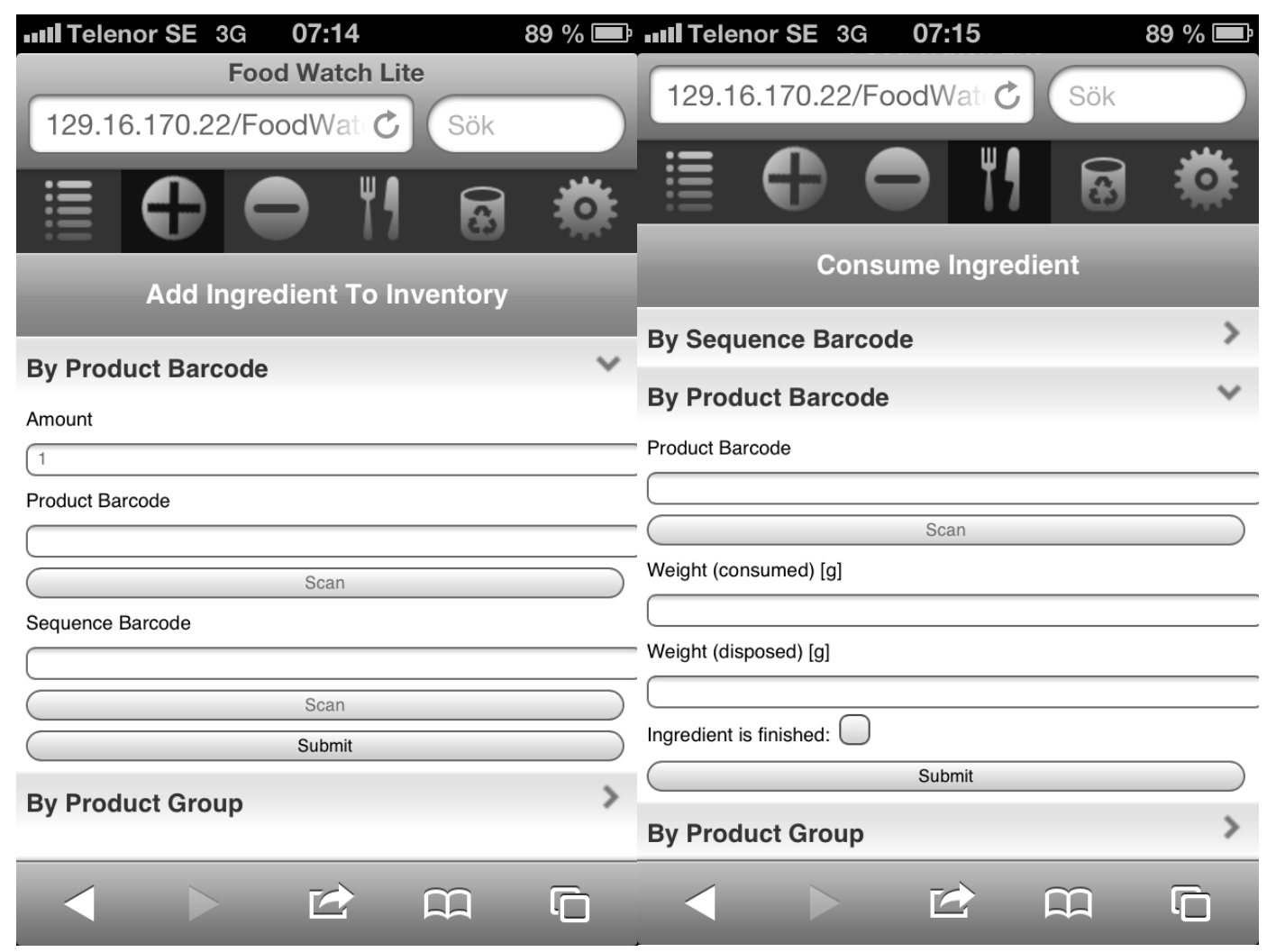

Figure 2: Structure and functionality of the FoodWatch application Left: Products can be added to the inventory using the product barcode, or the product group in case a product barcode is missing. Along with the product barcode or product group, a unique sequence barcode is also scanned in order to enable exact tracking of products. Right: Upon consumption of a product, or a fraction thereof, the sequence barcode is scanned and the weight consumed is recorded manually. The respective amount is removed from the inventory of that specific product. The same procedure holds also for products or fraction taken outside of the household or disposed of.

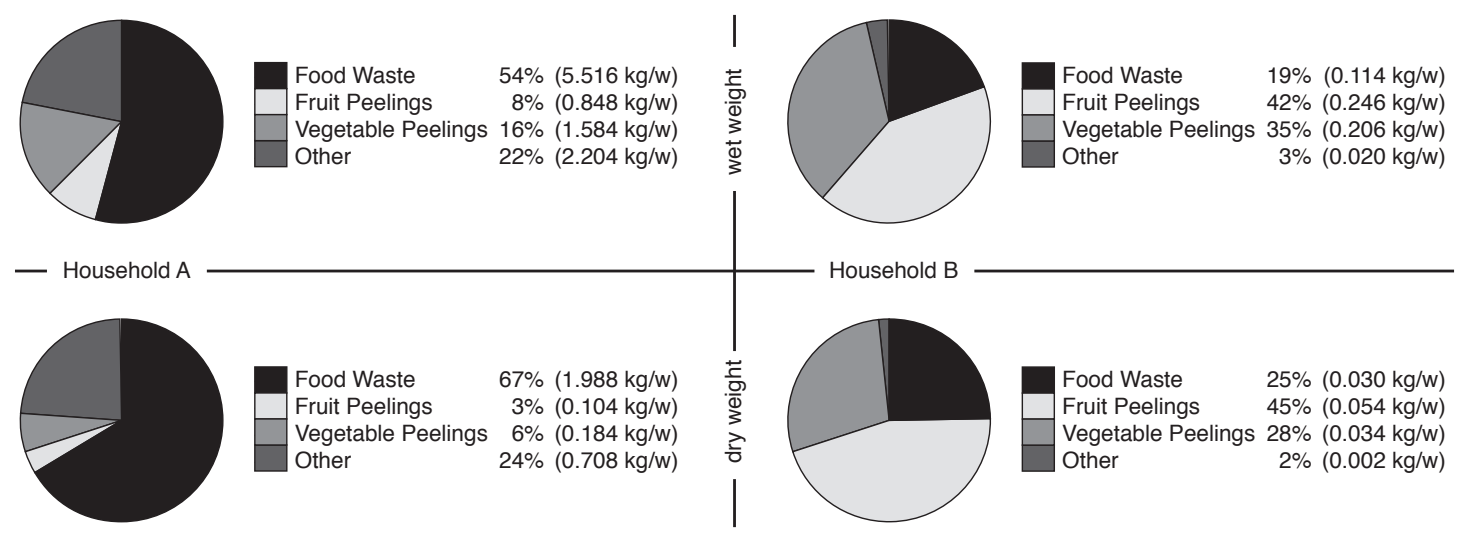

Figure 3: Disposal of food-related organic waste. Data was collected during the first stage, 3 May to 7 June, 2012. The graph represents both wet weight (top) and dry weight (bottom) for household A (left) and household B (right). Both the percentage and the absolute weight of the respective four fractions are indicated in the graph. Both the percentage of food waste and the absolute numbers are substantially higher for household A ( 2 adults, 5 children) than for household B (1 adult), even on a per person basis. Units: $\mathrm{kg}=$ kilogram; $w \mathrm{k}=$ week. 

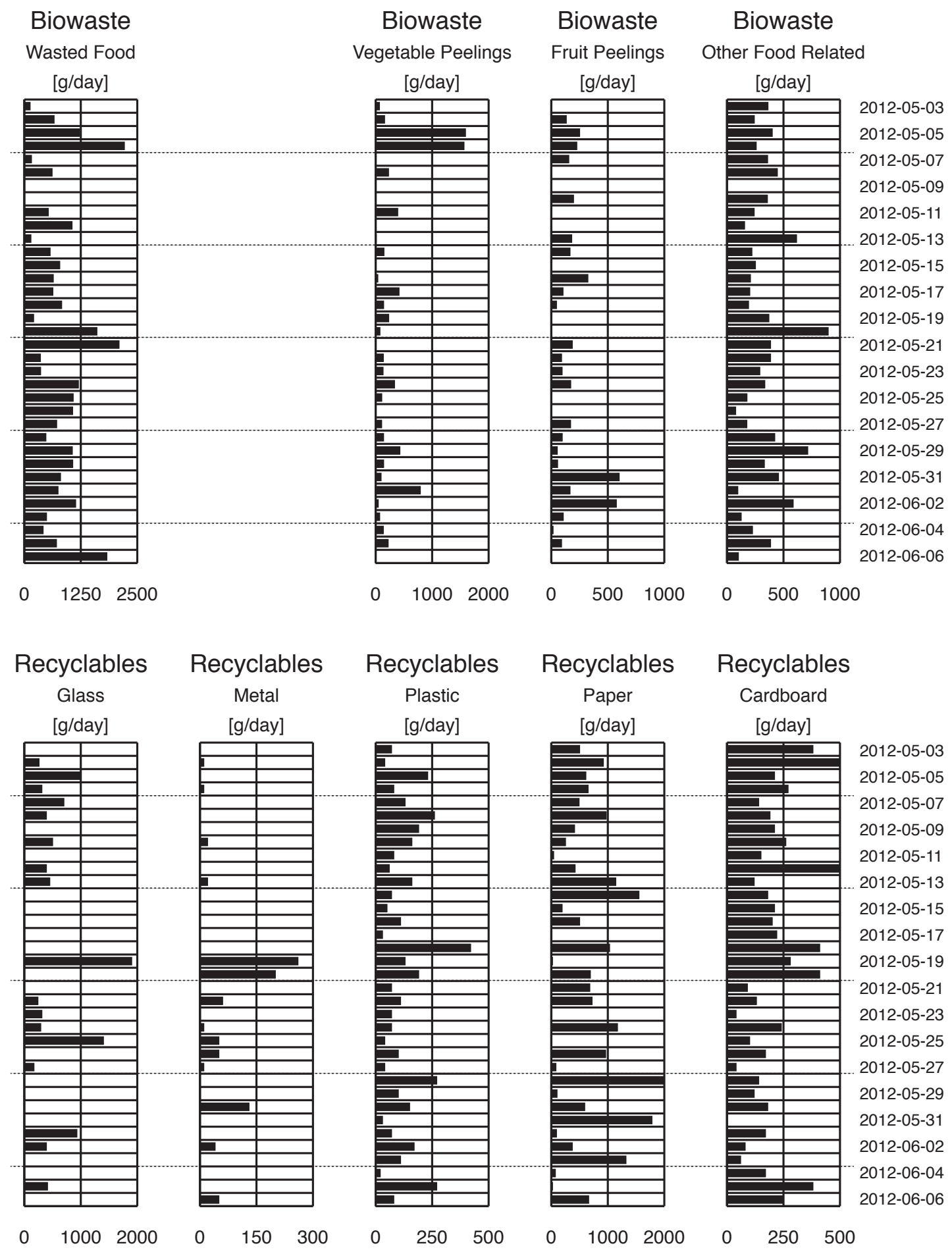

Figure 4: Daily disposal of various fractions of recyclables and organic waste at household A over a period of five weeks. To improve readability, different scales were used for different graphs. On the weekend of the 19th of May 2012, there is a distinct peak for both disposal of glass and metal coinciding with a relatively high disposal of other packaging material and a peak in disposed biowaste. Units: $\mathrm{d}=$ day; $\mathrm{g}=$ gram. Date format: YYYY-MM-DD. 


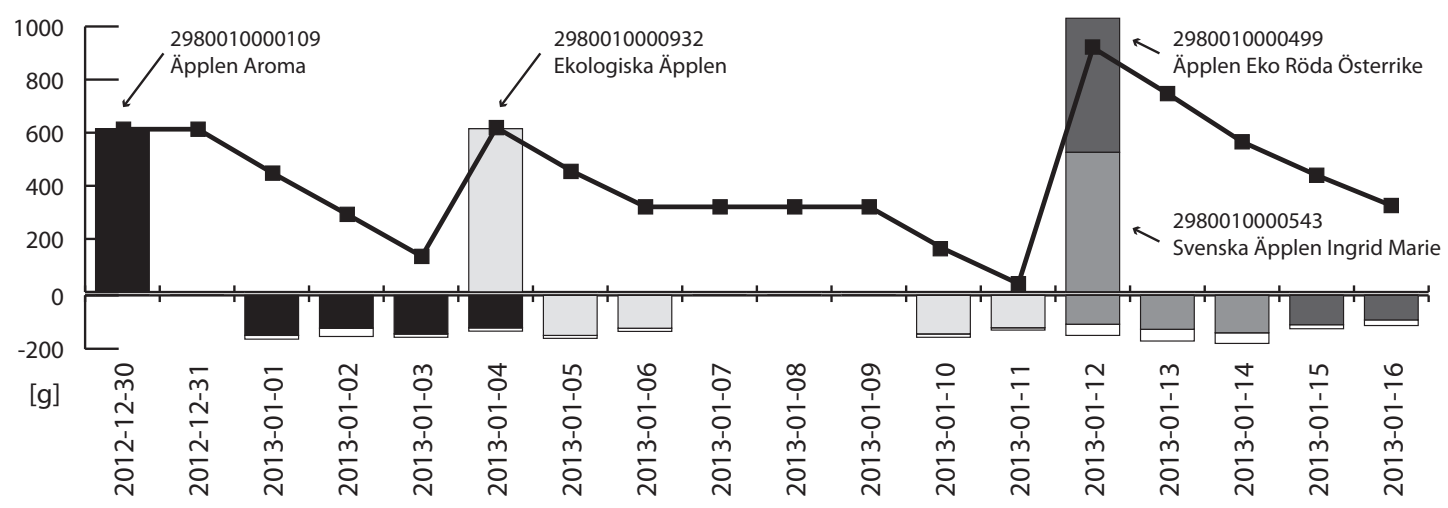

Figure 5: Product stock development for apples at household B. Columns on the positive axis represent addition to the inventory; columns on the negative axis represent removal from the inventory. Shaded columns represent purchase and consumption related to a specific batch (i.e. sequence barcode), whilst the white parts of the columns represent the fraction of the apple consumed that is disposed of as biowaste. This type of data is particularly useful to investigate household food management practices. Units: $g=$ gram.

\section{TABLES}

Table 1: Extent of data collection using the two data collection approaches: the triangulation of shopping receipt and waste component analysis, and the application of a smartphone WebApp. Units: $\mathrm{d}=$ day; $\mathrm{kg}=$ kilogram; $\mathrm{wk}=$ week .

\begin{tabular}{|c|c|c|c|}
\hline \multirow{2}{*}{\multicolumn{2}{|c|}{$\begin{array}{l}\text { TRIANGULATION APPROACH } \\
\text { Shonning reint }\end{array}$}} & \multirow[t]{2}{*}{ Household A } & \multirow[t]{2}{*}{ Household B } \\
\hline & & & \\
\hline Duration of data collection & [d] & 85 & 85 \\
\hline Days where nobody was at home & [d] & 0 & 27 \\
\hline Number of articles purchased & {$[-]$} & 1334 & 316 \\
\hline of which with weight indication & {$[-]$} & 287 & 73 \\
\hline Number of unique articles & {$[-]$} & 567 & 160 \\
\hline \multicolumn{4}{|l|}{ Waste component analysis: recyclables } \\
\hline Duration of data collection & [d] & 85 & 85 \\
\hline Days where nobody was at home & {$[\mathrm{d}]$} & 0 & 27 \\
\hline Number of product packages disposed of & {$[-]$} & 1079 & 203 \\
\hline of which with weight indication & {$[-]$} & 1042 & 142 \\
\hline Number of unique packaging items & {$[-]$} & 577 & 140 \\
\hline Amount of recyclabes sorted & {$[\mathrm{kg}]$} & 106.5 & 9.2 \\
\hline of which cardboard & {$[\mathrm{kg}]$} & 16.8 & 1.9 \\
\hline of which glass & {$[\mathrm{kg}]$} & 35.7 & 2.0 \\
\hline of which metal & {$[\mathrm{kg}]$} & 3.3 & 0.1 \\
\hline of which paper & {$[\mathrm{kg}]$} & 38.2 & 3.2 \\
\hline of which plastic & {$[\mathrm{kg}]$} & 12.2 & 2.1 \\
\hline of which wood & {$[\mathrm{kg}]$} & 0.3 & 0.0 \\
\hline \multicolumn{4}{|l|}{ Waste component analysis: organic waste } \\
\hline Duration of data collection & [d] & 35 & 35 \\
\hline Days where nobody was at home & [d] & 0 & 18 \\
\hline Number of samples & {$[-]$} & 118 & 35 \\
\hline Number of days with at least one non-zero sample & {$[-]$} & 34 & 15 \\
\hline Amount of organic waste analysed & {$[\mathrm{kg}]$} & 50.8 & 2.9 \\
\hline \multicolumn{4}{|l|}{ Estimated consumption } \\
\hline Total & {$[\mathrm{kg}]$} & 888 & 73 \\
\hline Weekly & {$[\mathrm{kg} / \mathrm{wk}]$} & 74.0 & 6.1 \\
\hline Weekly, corrected for days with absence ${ }^{1)}$ & {$[\mathrm{kg} / \mathrm{wk}]$} & 74.0 & 8.9 \\
\hline
\end{tabular}




\begin{tabular}{|c|c|c|c|}
\hline \multicolumn{2}{|l|}{$\begin{array}{l}\text { SMART PHONE WEB APP APPROACH } \\
\text { FoodWatch }\end{array}$} & \multicolumn{2}{|c|}{ Household B } \\
\hline Duration of data collection & [d] & & 15 \\
\hline Days where nobody was at home & {$[\mathrm{d}]$} & & 0 \\
\hline Food on stock (conservative) & {$[\mathrm{kg}]$} & (26 scans) & 6.05 \\
\hline Food purchased & {$[\mathrm{kg}]$} & (78 scans) & 32.48 \\
\hline Food taken out of the household & {$[\mathrm{kg}]$} & (4 scans) & 2.46 \\
\hline Food consumed within the household & {$[\mathrm{kg}]$} & (245 scans) & 15.03 \\
\hline Food disposed within the household & {$[\mathrm{kg}]$} & (82 scans) & 2.07 \\
\hline Food waste generated within the household & {$[\mathrm{kg}]$} & (3 scans) & 0.52 \\
\hline \multicolumn{4}{|l|}{ Estimated consumption } \\
\hline Total & {$[\mathrm{kg}]$} & & 17.62 \\
\hline Weekly & {$[\mathrm{kg} / \mathrm{wk}]$} & & 8.2 \\
\hline \multicolumn{4}{|c|}{$\begin{array}{l}\text { 1) Note that in household } \mathrm{B} \text {, nobody was at home during just under a third of the data collection period. The } \\
\text { respective weekly flows are thus shown once as average weekly consumption and once as weekly consumption } \\
\text { corrected for absence (i.e., average consumption while present). For household B this corrected estimate is on the } \\
\text { same order as the estimate obtained using the smartphone WebApp approach. These figures can be compared since } \\
\text { the flow estimate of the triangulation approach only captures food products, as the WebApp approach; non-food } \\
\text { products were recorded but normally no weight information was available. }\end{array}$} \\
\hline \multicolumn{4}{|c|}{$\begin{array}{l}\text { Note that for the FoodWatch WebApp approach, there was significantly more food added to the stock than } \\
\text { removed from the stock during the sampling period. The reason is that most packages added to the inventory (upon } \\
\text { purchase or first use, if already on stock in the household) were not entirely finished throughout the data collection } \\
\text { period. }\end{array}$} \\
\hline
\end{tabular}

Table 2: Product flows at households A and B estimated based on manual data collection (stage one). Estimates for food products that need to be consumed or processed within several days after purchase (e.g. fresh fruits and vegetables, fresh meat and dairy products) are based on both data sources (marked with $\S$ ). Estimates for food products that can be stored for extended periods after purchase (e.g. canned food, fruit juices) are based on disposed packaging only (marked with $\S \S$ ). For non-food products, weight indications are often lacking altogether (not marked). COICOP class 05.6.1 contains mostly detergents; COICOP class 12.3.1 contains mostly personal care products. Note the small overlap between data sources for most COICOP classes. ND, SD, D and S denote non-durable goods, semi-durable goods, durable goods and services, respectively. Units: $\mathrm{kg}=$ kilogram; wk $=$ week. The first row per COICOP class represents household A whereas the second row per COICOP class represents household B.

\begin{tabular}{|c|c|c|c|c|c|c|c|c|c|}
\hline \multirow[b]{2}{*}{ COICOP Class } & \multicolumn{5}{|c|}{ Number of items (12 weeks) } & \multicolumn{4}{|c|}{ Mass $[\mathrm{kg} / \mathrm{wk}]$} \\
\hline & $(1)$ & (2) & (3) & (4) & (5) & $(6)$ & (7) & (8) & (9) \\
\hline 01.1.1 (ND) $\S$ & 183 & 66 & 156 & 156 & 6 & 0.92 & 6.98 & 0.59 & 7.31 \\
\hline Bread and cereals & 52 & 22 & 18 & 18 & 0 & 0.01 & 0.52 & 0.00 & 0.53 \\
\hline $01.1 .2(\mathrm{ND}) \S$ & 120 & 110 & 119 & 119 & 31 & 2.80 & 5.55 & 2.00 & 6.35 \\
\hline Meat & 23 & 12 & 16 & 16 & 4 & 0.17 & 0.29 & 0.13 & 0.33 \\
\hline $01.1 .3(\mathrm{ND}) \S$ & 18 & 10 & 8 & 8 & 1 & 0.41 & 0.34 & 0.03 & 0.71 \\
\hline Fish and seafood & 3 & 1 & 0 & 0 & 0 & 0.02 & 0.00 & 0.00 & 0.02 \\
\hline $01.1 .4(\mathrm{ND}) \S$ & 190 & 28 & 206 & 195 & 8 & 0.56 & 16.58 & 0.42 & 16.72 \\
\hline Milk, cheese and eggs & 31 & 14 & 20 & 20 & 2 & 0.50 & 0.56 & 0.17 & 0.89 \\
\hline $01.1 .5(\mathrm{ND}) \S \S$ & 29 & 0 & 19 & 19 & 0 & 0.00 & 1.05 & 0.00 & 1.05 \\
\hline Oils and fats & 2 & 0 & 5 & 5 & 0 & 0.00 & 0.15 & 0.00 & 0.15 \\
\hline $01.1 .6(\mathrm{ND}) \S$ & 95 & 40 & 44 & 44 & 13 & 2.71 & 3.10 & 1.41 & 4.39 \\
\hline Fruit & 51 & 26 & 10 & 10 & 0 & 0.67 & 0.45 & 0.00 & 1.12 \\
\hline $01.1 .7(\mathrm{ND}) \S$ & 255 & 173 & 183 & 183 & 44 & 5.70 & 7.60 & 2.21 & 11.09 \\
\hline Vegetables & 62 & 44 & 36 & 33 & 5 & 1.13 & 1.12 & 0.15 & 2.10 \\
\hline $01.1 .8(\mathrm{ND}) \S \S$ & 10 & 0 & 6 & 6 & 0 & 0.00 & 0.46 & 0.00 & 0.46 \\
\hline Sugar, jam, honey, chocolate and confectionery & 9 & 0 & 8 & 8 & 0 & 0.00 & 0.13 & 0.00 & 0.13 \\
\hline $01.1 .9(\mathrm{ND}) \S$ & 76 & 27 & 68 & 64 & 4 & 0.28 & 2.13 & 0.09 & 2.32 \\
\hline Food products n.e.c. & 9 & 0 & 8 & 8 & 0 & 0.00 & 0.04 & 0.00 & 0.04 \\
\hline
\end{tabular}


This is a peer reviewed manuscript accepted for publication in the Journal of Industrial Ecology. The final version of this manuscript is available at http://dx.doi.org/10.1111/jiec.12111.

\begin{tabular}{|c|c|c|c|c|c|c|c|c|c|}
\hline $01.2 .1(\mathrm{ND}) \S \S$ & 11 & 0 & 11 & 11 & 0 & 0.00 & 0.48 & 0.00 & 0.48 \\
\hline Coffee, tea and cocoa & 3 & 3 & 1 & 1 & 0 & 0.02 & 0.01 & 0.00 & 0.03 \\
\hline $01.2 .2(\mathrm{ND}) \S \S$ & 76 & 55 & 83 & 83 & 0 & 0.22 & 9.42 & 0.00 & 9.42 \\
\hline $\begin{array}{l}\text { Mineral waters, soft drinks, fruit and vegetable } \\
\text { juices }\end{array}$ & 23 & 0 & 16 & 16 & 0 & 0.00 & 0.56 & 0.00 & 0.56 \\
\hline 02.1 .1 (ND) $\S \S$ & 1 & 1 & 1 & 1 & 0 & 0.03 & 0.08 & 0.00 & 0.11 \\
\hline Spirits & 0 & 0 & 0 & 0 & 0 & 0.00 & 0.00 & 0.00 & 0.00 \\
\hline $02.1 .2(\mathrm{ND}) \S \S$ & 34 & 34 & 42 & 42 & 26 & 3.25 & 3.81 & 2.58 & 4.48 \\
\hline Wine & 0 & 0 & 3 & 3 & 0 & 0.00 & 0.09 & 0.00 & 0.09 \\
\hline $02.1 .3(\mathrm{ND}) \S \S$ & 26 & 26 & 38 & 38 & 26 & 1.02 & 1.47 & 1.02 & 1.47 \\
\hline Beer & 0 & 0 & 0 & 0 & 0 & 0.00 & 0.00 & 0.00 & 0.00 \\
\hline 03.1 .2 (SD) & 2 & 0 & 0 & 0 & 0 & 0.00 & 0.00 & 0.00 & 0.00 \\
\hline Garments & 0 & 0 & 5 & 0 & 0 & 0.00 & 0.00 & 0.00 & 0.00 \\
\hline 04.5 .4 (ND) & 3 & 0 & 1 & 1 & 0 & 0.00 & 0.17 & 0.00 & 0.17 \\
\hline Solid fuels & 0 & 0 & 0 & 0 & 0 & 0.00 & 0.00 & 0.00 & 0.00 \\
\hline 05.2 .0 (SD) & 2 & 0 & 0 & 0 & 0 & 0.00 & 0.00 & 0.00 & 0.00 \\
\hline Household textiles & 1 & 0 & 8 & 0 & 0 & 0.00 & 0.00 & 0.00 & 0.00 \\
\hline $05.4 .0(\mathrm{SD})$ & 5 & 0 & 3 & 0 & 0 & 0.00 & 0.00 & 0.00 & 0.00 \\
\hline Glassware, tableware and household & 0 & 0 & 4 & 0 & 0 & 0.00 & 0.00 & 0.00 & 0.00 \\
\hline 05.6.1 (ND) & 142 & 0 & 29 & 26 & 0 & 0.00 & 5.39 & 0.00 & 5.39 \\
\hline Non-durable household goods & 21 & 1 & 7 & 1 & 0 & 0.08 & 0.08 & 0.00 & 0.08 \\
\hline $06.1 .1(\mathrm{ND})$ & 1 & 0 & 5 & 0 & 0 & 0.00 & 0.00 & 0.00 & 0.00 \\
\hline Pharmaceutical products & 0 & 0 & 16 & 0 & 0 & 0.00 & 0.00 & 0.00 & 0.00 \\
\hline $09.1 .3(\mathrm{D})$ & 1 & 0 & 1 & 0 & 0 & 0.00 & 0.00 & 0.00 & 0.00 \\
\hline Information processing equipment & 0 & 0 & 7 & 0 & 0 & 0.00 & 0.00 & 0.00 & 0.00 \\
\hline $09.2 .1(\mathrm{D})$ & 1 & 0 & 0 & 0 & 0 & 0.00 & 0.00 & 0.00 & 0.00 \\
\hline Major durables for outdoor recreation & 0 & 0 & 0 & 0 & 0 & 0.00 & 0.00 & 0.00 & 0.00 \\
\hline $09.3 .3(\mathrm{ND})$ & 16 & 0 & 0 & 0 & 0 & 0.00 & 0.00 & 0.00 & 0.00 \\
\hline Gardens, plants and flowers & 15 & 0 & 0 & 0 & 0 & 0.00 & 0.00 & 0.00 & 0.00 \\
\hline $09.3 .4(\mathrm{ND})$ & 4 & 0 & 4 & 4 & 0 & 0.00 & 0.77 & 0.00 & 0.77 \\
\hline Pets and related products & 0 & 0 & 0 & 0 & 0 & 0.00 & 0.00 & 0.00 & 0.00 \\
\hline 09.5 .1 & 1 & 0 & 0 & 0 & 0 & 0.00 & 0.00 & 0.00 & 0.00 \\
\hline Books & 0 & 0 & 0 & 0 & 0 & 0.00 & 0.00 & 0.00 & 0.00 \\
\hline $09.5 .2(\mathrm{ND})$ & 2 & 0 & 0 & 0 & 0 & 0.00 & 0.00 & 0.00 & 0.00 \\
\hline Newspapers and periodicals & 0 & 0 & 0 & 0 & 0 & 0.00 & 0.00 & 0.00 & 0.00 \\
\hline 09.5.4 (ND) & 2 & 0 & 0 & 0 & 0 & 0.00 & 0.00 & 0.00 & 0.00 \\
\hline Stationery and drawing materials & 3 & 0 & 4 & 0 & 0 & 0.00 & 0.00 & 0.00 & 0.00 \\
\hline 12.1.3 (ND) & 28 & 0 & 45 & 45 & 0 & 0.00 & 1.08 & 0.00 & 1.08 \\
\hline $\begin{array}{l}\text { Other appliances, articles and products for } \\
\text { personal care }\end{array}$ & 7 & 2 & 4 & 3 & 2 & 0.01 & 0.05 & 0.01 & 0.05 \\
\hline $12.3 .2(\mathrm{SD})$ & 0 & 0 & 0 & 0 & 0 & 0.00 & 0.00 & 0.00 & 0.00 \\
\hline Other personal effects & 1 & 0 & 0 & 0 & 0 & 0.00 & 0.00 & 0.00 & 0.00 \\
\hline $01-12$ & 1334 & 570 & 1072 & 1045 & 159 & 17.89 & 66.47 & 10.35 & 74.01 \\
\hline TOTAL & 316 & 125 & 196 & 142 & 13 & 2.61 & 4.05 & 0.46 & 6.11 \\
\hline \multicolumn{10}{|c|}{$\begin{array}{l}\text { (1) = total number of items purchased*; }(2)=\text { of which with weight indication; }(3)=\text { total number of items } \\
\text { disposed**; }(4) \text { of which with weight indication; }(5) \text { overlap between data sources; }(6)=\text { estimate based on } \\
\text { receipts (extrapolation***); }(7)=\text { estimate based on disposed packaging (extrapolation***); }(8)=\text { overlap } \\
\text { between data sources; }(9)=\text { estimate based on triangulation of both data sources }\end{array}$} \\
\hline \multicolumn{10}{|c|}{$\begin{array}{l}\text { * One item purchased equals one shopping receipt item. For products bought by package, one item purchased } \\
\text { thus equals one package. For products bought by weight, several products of the same type count as one item } \\
\text { purchase (e.g., three apples of the same kind count as one item as they appear on the shopping receipt as one } \\
\text { item). }\end{array}$} \\
\hline \multicolumn{10}{|l|}{ ** One item disposed equals one package. } \\
\hline \multicolumn{10}{|c|}{$\begin{array}{l}\text { *** Values were extrapolated as follows: 'extrapolated estimate' }=\text { 'weight of all products with weight } \\
\text { indication' / 'number of products with weight indication (purchased or disposed)' } \mathrm{x} \text { 'total number of products } \\
\text { (purchased or disposed)'. }\end{array}$} \\
\hline
\end{tabular}

Table 3: Overview of food products required to cook rice with vegetables for one person. The table indicates when the respective food products were bought (i.e. added to the inventory) and which fraction was consumed or biowaste. Note that an asterisk behind the timestamp of addition to the inventory means that the respective product was already in the household at the time data collection started. Abbreviations: $\mathrm{n} . \mathrm{a} .=$ not available. Units: $\mathrm{g}=$ gram. 
This is a peer reviewed manuscript accepted for publication in the Journal of Industrial Ecology. The final version of this manuscript is available at http://dx.doi.org/10.1111/jiec.12111.

\begin{tabular}{|c|c|c|c|c|}
\hline $\begin{array}{l}\text { Sequence barcode / Product barcode } \\
\text { COICOP code / Product group } \\
\text { Product description }\end{array}$ & $\begin{array}{c}\text { Date and amount } \\
\text { originally added to } \\
\text { inventory }\end{array}$ & $\begin{array}{l}\text { Date and amount } \\
\text { (partly) removed } \\
\text { from inventory }\end{array}$ & $\begin{array}{l}\text { of which } \\
\text { consumed }\end{array}$ & $\begin{array}{l}\text { of which } \\
\text { biowaste }\end{array}$ \\
\hline $\begin{array}{l}2980010000420 \text { / } 7316150674200 \\
\text { 01.1.5 / Olive Oil } \\
\text { Fontana Extra Virgin Olivolja Original }\end{array}$ & $\begin{array}{c}2012-12-3000: 00^{*} \\
500 \mathrm{~g}\end{array}$ & $\begin{array}{c}2013-01-05 \text { 17:44 } \\
22 \mathrm{~g}\end{array}$ & $\begin{array}{c}22 \mathrm{~g} \\
(100 \%)\end{array}$ & $\begin{array}{c}0 \mathrm{~g} \\
(0 \%)\end{array}$ \\
\hline $\begin{array}{l}2980010000840 / 7318693303944 \\
01.1 .7 \text { / Carrot } \\
\text { ICA Eko Morötter }\end{array}$ & $\begin{array}{c}2012-12-3022: 23 \\
1000 \mathrm{~g}\end{array}$ & $\begin{array}{c}2013-01-05 \text { 17:53 } \\
248 \mathrm{~g}\end{array}$ & $\begin{array}{l}213 \mathrm{~g} \\
(86 \%)\end{array}$ & $\begin{array}{c}35 \mathrm{~g} \\
(14 \%)\end{array}$ \\
\hline $\begin{array}{l}\text { 2980010000970 / n.a. } \\
01.1 .7 \text { / Pumpkin } \\
\text { Pumpkin } \\
\end{array}$ & $\begin{array}{c}2012-12-3110: 49 \\
1827 \mathrm{~g}\end{array}$ & $\begin{array}{c}\text { 2013-01-05 18:05 } \\
301 \mathrm{~g}\end{array}$ & $\begin{array}{l}278 \mathrm{~g} \\
(92 \%)\end{array}$ & $\begin{array}{l}23 \mathrm{~g} \\
(8 \%)\end{array}$ \\
\hline $\begin{array}{l}2980010000208 / \text { n.a. } \\
\text { 01.1.7 / Leek } \\
\text { Leek }\end{array}$ & $\begin{array}{c}2012-12-3022: 25 \\
305 \mathrm{~g}\end{array}$ & $\begin{array}{c}2013-01-05 \text { 18:09 } \\
93 \mathrm{~g}\end{array}$ & $\begin{array}{l}90 \mathrm{~g} \\
(97 \%)\end{array}$ & $\begin{array}{c}3 \mathrm{~g} \\
(3 \%)\end{array}$ \\
\hline $\begin{array}{l}\text { 2980010000871 / n.a. } \\
\text { 01.1.1 / Rice Grain } \\
\text { Basmati Rice }\end{array}$ & $\begin{array}{c}2013-12-3000: 00^{*} \\
383 \mathrm{~g}\end{array}$ & $\begin{array}{c}\text { 2013-01-05 18:15 } \\
112 \mathrm{~g}\end{array}$ & $\begin{array}{c}112 \mathrm{~g} \\
(100 \%)\end{array}$ & $\begin{array}{l}0 \mathrm{~g} \\
(0 \%)\end{array}$ \\
\hline
\end{tabular}

\section{REFERENCES}

Abu Qdais, H.A., M.F. Hamoda, and J. Newham. 1997. Analysis of residential solid waste at generation sites. Waste Management and Research 15: 395-406.

Baccini, P. and H.-P. Bader. 1996. Regionaler Stoffhaushalt - Erfassung, Bewertung und Steuerung [Regional metabolism - Quantification, evaluation and control]. Heidelberg, Germany: Spektrum Akademischer Verlag.

Baker, L., P. Hartzheim, S. Hobbie, J. King, and K. Nelson. 2007. Effect of consumption choices on fluxes of carbon, nitrogen and phosphorus through households. Urban Ecosystems 10(2): 97-117.

Bandara, N.J.G.J., J.P.A. Hettiaratchi, S.C. Wirasinghe, and S. Pilapiiya. 2007. Relation of waste generation and composition to socio-economic factors: A case study. Environmental Monitoring and Assessment 135: 31-39.

Barbiroli, G. 2006. Eco-efficiency or/and eco-effectiveness? Shifting to innovative paradigms for resource productivity. International Journal of Sustainable Development and World Ecology 13(5): 391-395.

Benders, R.M.J., H.C. Moll, and D.S. Nijdam. 2012. From energy to environmental analysis: Improving the resolution of the environmental impact of Dutch private consumption with hybrid analysis. Journal of Industrial Ecology 16(2): 163175.

Bin, S. and H. Dowlatabadi. 2005. Consumer lifestyle approach to US energy use and the related CO2 emissions. Energy Policy 33: 197-208.

Bulkeley, H. and K. Askins. 2009. Waste interfaces: Biodegradable waste, municipal policy and everyday practice. The Geographical Journal 175(4): 251-260.

Bulkeley, H. and N. Gregson. 2009. Crossing the threshold: Municipal waste policy and household waste generation. Environment and Planning A 41: 929-945.

Carlsson-Kanyama, A., R. Karlsson, H. Moll, and R. Kok. 2002. Household metabolism in the five cities. FMS Report 177. Stockholm, Sweden: Forskningsgruppen för Miljöstrategiska Studier.

Codoban, N. and C.A. Kennedy. 2008. Metabolism of neighborhoods. Journal of Urban Planning and Development 134(1): 21-31. 
Cohn, G., S. Gupta, J. Froehlich, E. Larson, and S.N. Patel. 2010. GasSense: Appliance-level, single-point sensing of gas activity in the home. Lecture Notes in Computer Science 6030: 265-282.

Cooper, T. 2005. Slower consumption: Reflections on product life spans and the "throwaway society". Journal of Industrial Ecology 9(1-2): 51-67.

Dahlén, L. and A. Lagerkvist. 2008. Methods for household waste composition studies. Waste Management 28: 1100-1112.

Dahlén, L., S. Vukicevic, J.-E. Meijer, and A. Lagerkvist. 2007. Comparison of different collection systems for sorted household waste in Sweden. Waste Management 27: 1298-1305.

Doyle, R., and A.R. Davies. 2013. Towards sustainable household consumption: Exploring a practice oriented, participatory backcasting approach for sustainable home heating practices in Ireland. Journal of Cleaner Production 48: 260 271.

Evans, D. 2011. Thrifty, green or frugal: Reflections on sustainable consumption in a changing economic climate. Geoforum 42(5): 550-557.

Froehlich, J. 2011. Sensing and feedback of everyday activities to promote environmental behaviors. Ph.D. thesis, University of Washington, Seattle.

Froehlich, J., T. Dillahunt, P. Klasnja, J. Mankoff, S. Consolvo, B. Harrison, and J.A. Landay. 2009. Ubigreen: Investigating a mobile tool for tracking and supporting green transportation habits. Proceedings of the 2009 ACM SIGCHI Conference on Human Factors in Computing Systems: 1043-1052.

Froehlich, J., L. Findlater, and J. Landay. 2010. The Design of Eco-Feedback Technology. Proceedings of the 2010 ACM SIGCHI Conference on Human Factors in Computing Systems: 1999-2008.

Froehlich, J., E. Larson, S. Gupta, G. Cohn, M.S. Reynolds, and S.N. Patel. 2011. Disaggregated end-use energy sensing for the smart grid. IEEE Pervasive Computing 10(1): 28-39.

Frye-Levine, L.A. 2012. Sustainability through design science: Re-imagining option spaces beyond eco-efficiency. Sustainable Development 20: 166-179.

Gilg, A., S. Barr, and N. Ford. 2005. Green consumption or sustainable lifestyles? Identifying the sustainable consumer. Futures 37: 481-504.

Giljum, S., F. Hinterberger, M. Bruckner, E. Burger, J. Frühmann, S. Lutter, E. Pirgmaier, Ch. Polzin, H. Waxwender, L. Kernegger, and M. Warhurst. 2009. Overconsumption? - Our use of the world's natural resources. Vienna, Austria: SERI, GLOBAL 2000, Friends of the Earth Europe.

GoodGuide. 2013. GoodGuide. www.goodguide.com. Accessed 4 April 2013.

Gram-Hanssen, K. 2010. Standby consumption in households analyzed with a practice theory approach. Journal of Industrial Ecology 14(1): 150-165.

Gupta, S., M.S. Reynolds, and S.N. Patel. 2010. ElectriSense: Single-point sensing using EMI for electrical event detection and classification in the home. Proceedings of the 2010 ACM Conference on Ubiquitous Computing: 139-148.

Hertwich, E.G. 2005. Life cycle approaches to sustainable consumption: A critical review. Environmental Science and Technology 39(13): 4673-4684. 
Hertwich, E.G. 2011. The life cycle environmental impacts of consumption. Economic Systems Research 23(1): 27-47.

Holden, E. 2004. Towards sustainable consumption: Do green households have smaller ecological footprints? International Journal of Sustainable Development 7(1): 44-58.

Holden, E. and K. Linnerud. 2010. Environmental attitudes and household consumption: An ambiguous relationship. International Journal of Sustainable Development 13(3): 217-231.

Hunter, C., K. Carmichael, and K. Pangbourne. 2006. Household ecological footprinting using a new diary-based data-gathering approach. Local Environment 11(3): 307-327.

Isenhour, C. 2010. On conflicted Swedish consumers, the effort to stop shopping and neoliberal environmental governance. Journal of Consumer Behaviour 9: 454 469.

Jain, R.K., J.E. Taylor, and P.J. Culligan. 2013. Investigating the impact eco-feedback information representation has on building occupant energy consumption behavior and savings. Energy and Buildings 64: 408-414.

Kitzes, J., M. Wackernagel, J. Loh, A. Peller, S. Goldfinger, D. Cheng, and K. Tea. 2008. Shrink and share: Humanity's present and future ecological footprint. Philosophical Transactions of The Royal Society B 363: 467-475.

Korhonen, J. and T.P. Seager. 2008. Beyond eco-efficiency: A resilience perspective. Business Strategy and the Environment 17: 411-419.

Kotakorpi, E., S. Lähteenoja, and M. Lettenmeier. 2008. Household MIPS - Natural resource consumption of Finnish households and its reduction. Helsinki, Finland: Ministry of the Environment.

Kuijer, L. and A. de Jong. 2012. Identifying design opportunities for reduced household resource consumption: Exploring practices of thermal comfort. Journal of Design Research 10(1/2): 67-85.

Larson, E., J. Froehlich, T. Campbell, C. Haggerty, L. Atlas, J. Fogarty, and S.N. Patel. 2012. Disaggregated water sensing from a single, pressure-based sensor: An extended analysis of hydrosense using staged experiments. Pervasive and Mobile Computing 8: 82-102.

Lebersorger, S. and P. Beigl. 2011. Municipal solid waste generation in municipalities: Quantifying impacts of household structure, commercial waste and domestic fuel. Waste Management 31(9-10): 1907-1915.

McCalley, L.T., P.W. de Vries, and C.J.H. Midden. 2011. Consumer response to product-integrated energy feedback: Behavior, goal level shifts, and energy conservation. Environment and Behaviour 43(4): 525-545.

Moll, H.C., K.J. Noorman, R. Kok, R. Engström, H. Throne-Holst, and C. Clark. 2005. Pursuing more sustainable consumption by analyzing household metabolism in European countries and cities. Journal of Industrial Ecology 9(12): 259-275.

Tao, H., M.A. Brenckle, M. Yang, J. Zhang, M. Liu, S.M. Siebert, R.D. Averitt, M.S. Mannoor, M.C. McAlpine, J.A. Rogers, D.L. Kaplan, and F.G. Omenetto. 
2012. Silk-Based Conformal, Adhesive, Edible Food Sensors. Advanced Materials 24: 1067-1072.

OpenEAN. 2013. Open EAN/GTIN Database. http://openean.kaufkauf.net. Accessed 4 April 2013.

Reid, L., C. Hunter, and P. W. Sutton. 2011. Rising to the challenge of environmental behaviour change: Developing a reflexive diary approach. Geoforum 42(6): 720-730.

Reid, L., P. Sutton, and C. Hunter. 2010. Theorizing the meso level: The household as a crucible of pro-environmental behaviour. Progress in Human Geography 34(3): 309-327.

Roubroeks, M., J. Ham, and C. Midden. 2011. When artificial social agents try to persuade people: The role of social agency on the occurrence of psychological reactance. International Journal of Social Robotics 3: 155-165.

SCB (Statistiska centralbyrån). 2013. Statistics Sweden, Household Economy. www.scb.se/Pages/TableAndChart_163554.aspx. Accessed July 2013.

Scott, K., C. Bakker, and J. Quist. 2012. Designing change by living change. Design Studies 33(3): 279-297.

Stamminger, R. 2011. Modelling resource consumption for laundry and dish treatment in individual households for various consumer segments. Energy Efficiency 4: 559-569.

Sterner, Th. and H. Bartelings. 1999. Household waste management in a Swedish municipality: Determinants of waste disposal, recycling and composting. Environmental and Resource Economics 13: 473-491.

Strengers, Y. 2011. Beyond demand management: Co-managing energy and water practices with Australian households. Policy Studies 32(1): 35-58.

Sundramoorthy, V., G. Cooper, N. Linge, and Q. Liu. 2011. Domesticating energy monitoring systems: Challenges and design concerns. IEEE Pervasive Computing 10(1): 20-27.

Thaler, R.H. and W. Tucker. Smarter information, smarter consumers: Changes in technology and disclosure rules will help shoppers make better decisions. Get ready for the rise of the "choice engine". Harvard Business Review 91 (1-2): 44-54.

Tukker, A., M.J. Cohen, K. Hubacek, and O. Mont. 2010. The impacts of household consumption and options for change. Journal of Industrial Ecology 14(1): 1329.

Tukker, A. and B. Jansen. 2006. Environmental impacts of products: A detailed review of studies. Journal of Industrial Ecology 10(3): 159-182.

Weinstein, M.P., E.R. Turner, and C. Ibáñez. 2013. The global sustainability transition: It is more than changing light bulbs. Sustainability: Science, Practice, and Policy 9(1): 4-15. 